\title{
O TRATAMENTO CONTÁBIL DO CAPITAL INTELECTUAL EM EMPRESAS COM VALOR DE MERCADO SUPERIOR AO VALOR CONTÁBIL
}

\author{
Joel Marques de Oliveira \\ Professor do Centro Universitário de Jaraguá do Sul - SC \\ Mestre em Administração pela FURB - Universidade Regional de Blumenau - SC \\ E-mail: Joel@mannes.com.br
}

\author{
Ilse Maria Beuren \\ Professora Titular da Universidade Federal de Santa Catarina - SC \\ E-Mail: beuren@cse.ufsc.br
}

\section{RESUMO}

Este artigo tem por objetivo sintetizar o resultado da pesquisa sobre o tratamento contábil que é aplicado ao capital intelectual, sob a ótica do processo de gestão, representado pelos conceitos e técnicas que são utilizados e que dão suporte à ação da administração, em empresas com valor de mercado superior ao valor contábil. Para atingir este propósito, o artigo consubstancia-se em uma pesquisa realizada em duas empresas de capital aberto, de Santa Catarina, que apresentam valor de mercado, considerado o valor das ações superior ao seu valor contábil. Observou-se que, embora as empresas pesquisadas possuam todas as características das organizações voltadas ao conhecimento e domínio tecnológico, o tratamento contábil do capital intelectual é algo ainda muito incipiente, e que, os critérios utilizados para mensurar, registrar e evidenciar as informações referentes ao capital humano, capital estrutural e capital de clientes, com vistas ao processo de gestão, é algo que ainda carece de uma sistematização, para que se possa refletir, por meio das demonstrações contábeis, alguma posição nesse sentido. Concluiu-se que as empresas pesquisadas, mesmo não possuindo as informações sistematizadas sobre as iniciativas de mensuração do capital intelectual, têm consciência da sua importância. No entanto, para que os gestores desses empreendimentos possam, efetivamente, utilizá-las como um diferencial competitivo no processo de gestão, as informações sistematizadas sobre o capital intelectual devem fazer parte dos relatórios gerados para a tomada de decisões.

Palavras-chave: tratamento contábil, capital intelectual, processo de gestão.

\section{ABSTRACT}

The objective of this article si to summarize the result of the research about the accounting treatment which is applied to the intellectual capital, through the management viewpoint, in companies with a market value superior than the accounting value. In order to reach this intention, the article is substantiated on a research carried out in two open capital companies, in SC, which have a market value, considered the action value superior than its accounting value. It was observed that, although the researched companies have all the characteristics of the organizations that aim to the technological knowledge and domain, the accounting treatment of the intellectual capital is still something too incipient and that the criteria used to measure, register and show up the human capital, structural capital and customer capital referred information with view to the management process, is something that still needs a systematization, so that it is possible to reflect, throughout the accounting demonstrations, some position on this sense. It was concluded that the researched companies, even without the systematized information about the initiative of the intelectual capital mensuration, are conscious about this importance. However, the intellectual capital systematized information must be part of the generated reports for the decion takings, so that the managers of these undertakings can effectively use them as a competitive differential in the management process.

Keywords: accounting treatment, intellectual capital, management process. 


\section{INTRODUÇÃO}

O atual ambiente, no qual se inserem os empreendimentos, está passando por um processo de transformação, que também implica mudanças nos métodos de gestão. Diante da inevitável globalização dos mercados, as mudanças nas responsabilidades de cunho social, ambiental e cultural tornam-se imperiosas para aquelas empresas que pretendem manter-se competitivas.

Nesse sentido, a fonte de valor para produtos, tais como computadores, softwares, telefonia celular, e até mesmo os produtos de consumo habituais, está sendo alterada, isto é, seus conteúdos físicos estão recebendo novos agregados, associados ao conhecimento. O principal agente transformador dos bens e serviços não se refere a nenhum ativo comumente encontrado nas demonstrações contábeis, e sim a um ativo pouco estudado e discutido pela contabilidade, mas que está se transformando num dos principais fatores de vantagem competitiva para as empresas. Este ativo é o capital intelectual.

No Brasil, especificamente, o fim da reserva de mercado em vários setores e a conseqüente entrada de produtos estrangeiros colocou o país em competição direta com grandes potências, cujos produtos possuem know-how e preços incomparáveis aos nacionais. Essa competição pode ameaçar as posições garantidas pelas empresas em décadas passadas.

As tendências verificadas, hoje são uma realidade, conforme foi percebido por ANTUNES (2000, p.18):

Esse período de gradativas mudanças, não só no Brasil, mas também na economia mundial, vivenciado mais intensamente nas últimas décadas, vem sendo apontado por vários estudiosos do assunto como um período de transição de uma Sociedade Industrial para uma Sociedade do Conhecimento. Pois, aos demais recursos existentes, e até então valorizados e utilizados na produção - terra, capital e trabalho - junta-se o conhecimento, alterando, principalmente, a estrutura econômica das nações e, sobretudo, a forma de valorizar o ser humano, já que só este detém o conhecimento.
Mas o que é conhecimento? Essa questão, de acordo com SVEIBY (1998, p.35), "tem ocupado a mente dos filósofos ao longo do tempo sem que se tenha chegado a qualquer consenso - não há nenhuma definição da palavra aceita de modo geral." Explica que a palavra "conhecimento" tem várias acepções, podendo significar informação, conscientização, saber, cognição, sapiência, percepção, experiência, qualificação, discernimento, competência, habilidade prática, capacidade, aprendizado, sabedoria, certeza, e assim por diante. Portanto, a definição depende do contexto em que o termo é empregado.

KLEIN (1998, p.15) esclarece que o conhecimento, em ambientes organizacionais, pode ser percebido através de dois domínios. O domínio fluído e o domínio institucional. No domínio fluído, "o conhecimento se origina e cresce a partir da intuição pessoal, redes pessoais que se formam fora dos organogramas formais, encontros casuais entre pessoas e a improvisação que desconhecem procedimentos-padrão para descobrir maneiras melhores de se fazerem as coisas." No domínio institucional, existe a estrutura, o controle e a mensuração. Neste caso, "o conhecimento é claramente definido em procedimentos, relatórios, memorandos e bases de dados. Geralmente, é compartilhado seletivamente através das linhas de comando oficiais."

Segundo ANTUNES (2000, p.18), "a aplicação do conhecimento, nas organizações, vem impactando, sobremaneira, seu valor, pois a materialização da aplicação desse recurso mais as tecnologias disponíveis e empregadas para atuar num ambiente globalizado produzem benefícios intangíveis, que Ihes agregam valor."

A esse conjunto de benefícios intangíveis denominou-se Capital Intelectual. STEWART (1998, p. XIII) afirma que "constitui a matéria intelectual conhecimento, informação, propriedade intelectual, experiência que pode ser utilizada para gerar riqueza. É a capacidade mental coletiva."

A contabilidade na perspectiva tradicional, tem como uma das suas principais finalidades controlar o patrimônio e apurar o resultado econômico-financeiro de uma entidade, o que continua importante até hoje. Entretanto, muito se tem comentado, nos últimos tempos, de que os relatórios fornecidos não 
retratam certas realidades, por estar, o valor contábil da empresa, muitas vezes, abaixo do valor de mercado de suas ações. A esse respeito, SVEIBY (1998, p.4) afirma que "o problema com relação a esses mistérios do mercado acionário é que os investidores são obrigados a encontrar suas próprias explicações para os mesmos. Eles podem ver o fluxo de caixa do ano anterior porque está registrado nos documentos financeiros, mas quando se trata de avaliar mudanças no valor dos ativos intangíveis que irão gerar fluxos de caixa futuros, eles não têm por onde se orientar."

Admitir o conhecimento como um recurso econômico, de acordo com ANTUNES (2000, p.13), impõe novos paradigmas na forma de valorizar o ser humano e mensurar o valor de uma organização, pois gera benefícios intangíveis que alteram seu patrimônio, fato este que está fazendo com que a contabilidade seja criticada por não estar retratando o real valor da empresa nas demonstrações contábeis.

Desse modo, conforme ANTUNES (1999, p.83), infere-se que:

Se forem incorporados outros itens ao patrimônio da organização e que criarão valor a médio e longo prazos, ou seja, que reverterão em lucro para a empresa, a Contabilidade deve se esforçar para identificar e mensurar tais itens, por meio de uma contabilização mais sistêmica do know-how organizacional, pois isto é de grande importância tanto gerencialmente, quanto para seus usuários externos.

Nesse sentido, entende-se que o desafio maior para os gestores dos empreendimentos, consiste em identificar e desenvolver continuamente os ativos do conhecimento e para que isso seja possível, a contabilidade precisa contribuir estabelecendo padrões para mensurar, registrar e evidenciar o capital intelectual, testando a sua viabilidade no que se refere ao contexto organizacional contemporâneo.

Assim o objetivo do presente estudo consistiu em verificar o tratamento contábil que é dado ao capital intelectual, sob a ótica do processo de gestão, representado pelos conceitos e técnicas que são utilizados e que dão suporte à ação da administração, em empresas cujo valor de mercado é superior ao valor contábil.

\section{PRESSUPOSTOS TEÓRICOS DO CAPITAL INTELECTUAL}

\subsection{Reconhecimento e mensuração do Ativo intangível}

Ao se estudar a evolução histórica quanto aos processos de reconhecimento e mensuração dos ativos intangíveis pela Contabilidade, pode-se observar que essa preocupação não é recente. No que concerne especificamente aos ativos humanos, conforme FLAMHOLTZ apud PACHECO (1996, p.34), desde os anos 60 tem acontecido nos Estados Unidos um número crescente de pesquisas, experiências e teorias tentando desenvolver métodos de contabilidade para os ativos humanos de uma organização. A evolução dessas pesquisas e a publicação de obras recentes que evidenciam iniciativas desta natureza em empresas, são o reconhecimento de que os ativos humanos têm um papel mais importante na economia atual do que tinham no passado.

No Brasil, alguns trabalhos já foram desenvolvidos relacionados a contabilização de recursos humanos, um ativo intangível, mas que ainda encontra resistência na contabilidade tradicional, em virtude de a entidade não possuir sua propriedade e dada a complexidade de the atribuir valor.

Embora ainda não se tenha encontrado unanimidade quanto a seu tratamento contábil, todo o interesse que o tema vem despertando, nos meios acadêmico e empresarial, durante tantos anos, adquire maior urgência à medida que os ativos intangíveis, consubstanciados no capital intelectual, ganham espaço primordial nas organizações de classe mundial.

\subsection{Modelos de Capital intelectual preconizados na teoria}

XAVIER (1998, p.111) menciona que, "a inteligência permitiu ao homem que sobrevivesse com suas limitações físicas em um ambiente hostil e criasse a civilização. A inteligência permitirá às organizações a sobrevivência em ambientes competitivos, mutantes e exigentes pelos quais passaremos no processo de globalização."

Os ciclos econômicos estão se tornando mais íngremes e mais curtos. Neste sentido, OLIVER 
(1999, p.17) cita que, "a Era Agrária cobriu vários séculos, porém a Era Industrial durou, aproximadamente, não mais do que 200 anos, e a Era da informação durou apenas um pouco mais de 50 anos." Afirma que essa tendência ajuda a compreender as crescentes taxas de mudanças verificadas na última metade do século $X X$, enfatizando que as pessoas nascidas após 1950, e que ainda estão vivas, são a primeira geração na história da humanidade a vivenciar o início e o fim de uma era econômica.

Nota-se que a ênfase dada na atualidade à gestão do capital intelectual é resultante dos desenvolvimentos econômico, industrial e cultural ocorridos. Segundo WIIG (1998, p.10), "esta noção é baseada na nova ênfase e explícita dependência da adição de valor competitivo aos produtos e serviços mediante a aplicação de especialização humana embutida ou direta - o conhecimento."

Assim, apresenta-se na seqüência, alguns dos principais modelos identificados na literatura consultada, que são utilizados por algumas empresas da Europa, principalmente as de paises da Escandinávia.

\subsubsection{Modelo de capital intelectual de Leif Edvinsson e Michael S. Malone}

EDVINSSON e MALONE (1998, p.31-32) mencionam que existem duas formas básicas para se caracterizar o capital intelectual: o capital humano e o capital estrutural.

\section{a) Capital humano}

Sugerem que é toda a capacidade, conhecimento, habilidade e experiências individuais dos empregados e gerentes.

\section{b) Capital estrutural}

Compreende a infra-estrutura, o arcabouço, o empowerment, que apóiam o capital humano, subdividindo-se em capital organizacional e capital de clientes.

O capital organizacional é o investimento da empresa em sistemas, instrumentos, filosofia operacional, que agilizam o fluxo do conhecimento pela organização, bem como em direção a áreas externas, como aquelas voltadas para os canais de suprimento e distribuição; capital de inovação, que é a capacidade de renovação e os resultados da inovação sob a forma de direitos comerciais amparados por lei, propriedade intelectual e outros ativos e talentos intangíveis utilizados para criar e colocar rapidamente no mercado novos produtos e serviços; e o capital de processos, que é constituído por processos, técnicas semelhantes às normas ISO 9000 e a programas direcionados aos empregados.

Por sua vez, o capital de clientes é o valor do relacionamento com os clientes. EDVINSSON e MALONE (1998, p.33) afirmam que o capital de clientes "sempre esteve presente, oculto sob a denominação de goodwill". Explicam que quando uma empresa é vendida por um valor maior que o contábil, a diferença significa o reconhecimento que a empresa possui junto à sua carteira de clientes; e que para mensurar esse relacionamento do capital de clientes, bastaria aplicar o valor presente líquido descontado do lucro médio por cliente ao longo dos anos de relacionamento. Entretanto, medir tal solidez e lealdade é o grande desafio para a categoria do capital de clientes.

\subsubsection{Modelo de capital intelectual de Karl Erik Sveiby}

SVEIBY (1998, p.195) também apresenta um conjunto de elementos para caracterizar o capital intelectual, atribuindo alguns indicadores para avaliação das competências individuais, da estrutura interna e da estrutura externa.

No que se refere às competências individuais, SVEIBY (1998, p.42-44) caracteriza-as como sinônimo tanto de saber quanto de conhecimento. Exemplifica dizendo que "a marca de um verdadeiro especialista não é a capacidade de enumerar e aplicar as regras, mas a segurança de quebrá-las e substituí-las por regras melhores." Classifica a competência dos funcionários em conhecimento explícito, habilidade, experiência, julgamento de valor e rede social:

a) conhecimento explícito - abrange conhecimento dos fatos e é adquirido, principalmente, pela informação, quase sempre pela educação formal;

b) habilidade - é a arte de saber fazer, envolve uma proficiência prática - física e mental - e é adquirida sobretudo por treinamento e prática; inclui o conhecimento de regras de procedimento e habilidade de comunicação;

c) experiência - é adquirida, principalmente, pela reflexão sobre erros e sucessos passados; 
d) julgamento de valor - são percepções do que o indivíduo acredita estar certo;

e) rede social - é formada pelas relações do indivíduo com outros seres humanos dentro de um ambiente e uma cultura transmitidos pela tradição.

Quanto à estrutura interna, SVEIBY (1998, p.93) caracteriza-a como sendo o fluxo de conhecimento dentro da organização - as patentes, os conceitos, os modelos e os sistemas de computação e administrativos que servem de suporte para os profissionais envolvidos no processo de criação de conhecimento com os clientes.

No que diz respeito a estrutura externa, SVEIBY (1998, p.12) define-a no contexto das relações com os clientes e fornecedores, marcas registradas e a reputação ou a imagem da empresa.

\subsubsection{Modelo de capital intelectual de Annie Brooking}

BROOKING apud ANTUNES (2000, p.78) define capital intelectual como uma combinação de ativos intangíveis, fruto das mudanças ocorridas nas áreas de tecnologia da informação, mídia e comunicação, que trazem benefícios intangíveis para as empresas e que capacitam seu funcionamento, podendo ser divididos em quatro categorias: ativos de mercado, ativos humanos, ativos de propriedade intelectual e ativos de infra-estrutura.

Os ativos de mercado consistem do potencial que a empresa possui em decorrência dos intangíveis que estão relacionados ao mercado, por exemplo, marcas, clientes, lealdade dos clientes, canais de distribuição e franquias.

Os ativos humanos referem-se a tudo que o indivíduo pode gerar de benefício para as organizações por meio de sua experiência, conhecimento, criatividade e habilidade para resolver problemas.

No que concerne aos ativos de propriedade intelectual, são os que necessitam de proteção legal para proporcionarem às organizações benefícios, tais como know-how, segredos industriais, copyright, patentes, designs.

Os ativos de infra-estrutura consubstanciam-se das tecnologias, metodologias e dos processos empregados, como cultura, sistema de informação, métodos gerenciais, aceitação de risco, banco de dados dos clientes, etc.
Os modelos apresentados evidenciam várias tentativas empreendidas para desenvolver critérios que auxiliem a gestão, a mensuração, o registro e a evidenciação do capital intelectual. Diante da complexidade do tema, talvez não seja possível elaborar um modelo que seja único para os vários tipos de organizações. Entretanto, a essência principal dos modelos não deve variar significativamente.

\subsection{Formas de mensuração e contabilização do capital intelectual}

MOCK e GROVE apud GUERREIRO (1989, p.80) definem formas de mensuração como sendo o "conjunto de procedimentos que atribui números a objetos e eventos com o objetivo de prover informações válidas, confiáveis, apropriadas e econômicas para os tomadores de decisões."

Neste sentido, BEUREN (1994, p.52) esclarece que "estruturar um modelo de mensuração que possa ser aplicado a objetos ou eventos que ainda estão por se realizar certamente é mais complexo, visto que estas medidas referem-se a estimativas subjetivas."

Diante disso, a questão que permeia essa discussão é como medir o capital intelectual e determinar seu valor. Percebe-se que a mensuração do capital intelectual, de certa forma, já vem sendo realizada pelo próprio mercado quando atribui valor a uma determinada empresa, quase sempre, bastante superior àquele encontrado nos registros contábeis.

Não foram identificados na literatura, métodos padronizados para a mensuração do capital intelectual. Entretanto, algumas formas interessantes têm sido desenvolvidas.

\subsubsection{Metodologia de Leif Edvinsson e Michael S. Malone}

Se a parte oculta da empresa pode ser representada pelo capital intelectual, o capital físico mais o capital financeiro representam a parte visível. Desse modo, EDVINSSON e MALONE (1998, p.9) mencionam que o valor da empresa pode ser obtido conforme apresenta-se na Figura 1, que é o esquema utilizado pela empresa Sueca Skandia, para mensuração do seu capital intelectual. 


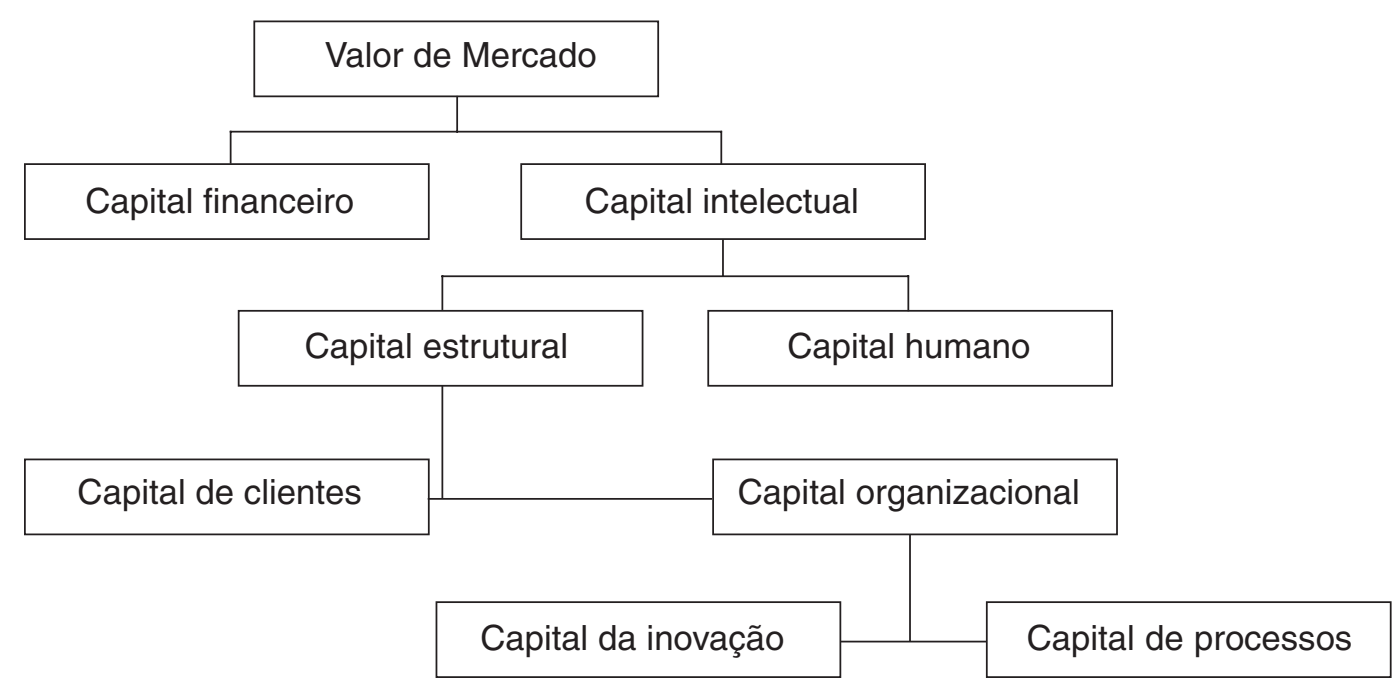

FONTE: EDVINSSON e MALONE (1998, p.47)

Figura 1 - Mensuração do capital intelectual segundo Edvinsson e Malone

Percebe-se que da mensuração do capital intelectual resultarão indicadores sobre o comportamento dos elementos que compõem o capital humano e o capital estrutural. Para cada componente desses elementos foram estabelecidos indicadores específicos por área de negócios, e outros indicadores comuns a toda a organização, com vistas à mensurar o capital intelectual para fins de utilização interna ou para comparações com outras empresas.

A empresa sueca Skandia é uma das pioneiras, que se tem notícias, que se utiliza dessa metodologia para mensurar o capital intelectual, através do seu Intellectual Capital Report-Relatório de Capital Intelectual.

\subsubsection{Metodologia de Karl Erik Sveiby}

SVEIBY (1998, p.14) também desenvolveu uma metodologia para mensurar o capital intelectual, a partir da divisão dos itens componentes do capital intelectual. Dividiu os ativos em tangíveis e intangíveis. Os ativos tangíveis correspondem aos bens, direitos e obrigações constantes do balanço patrimonial. Os intangíveis dividiu em competências individuais, estrutura interna e estrutura externa, considerandoos como a parte invisível do balanço patrimonial.

A Figura 2 representa a metodologia desenvolvida por Karl Erik Sveiby para mensuração do capital intelectual, dividindo o valor da empresa em indicadores tangíveis e recursos intangíveis, subdivididos em quatro categorias: crescimento, renovação, eficiência e estabilidade/risco.

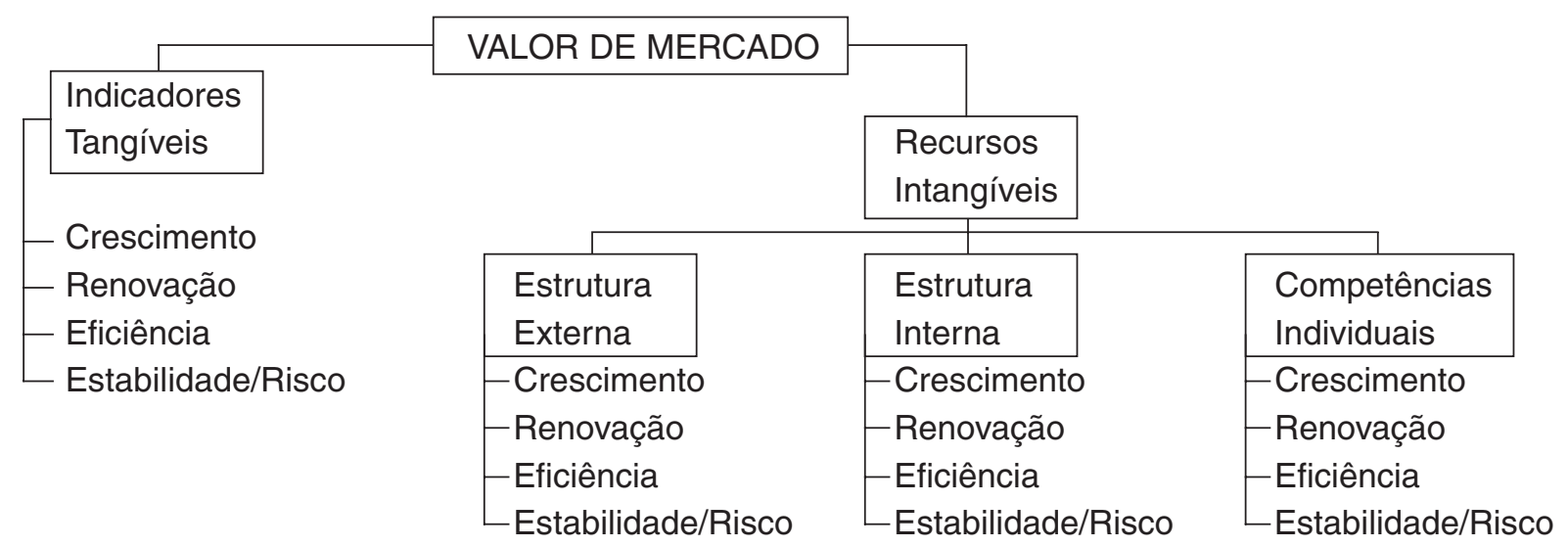

FONTE: SVEIBY (1998, p. 188) e Celemi's Intangible Assets Monitor. Disponivel em: <http://www.celemi.com/company/monitor99.asp> Acesso em: 16 set.2001.

Figura 2 - Mensuração dos ativos Intangíveis segundo Sveiby 
O modelo desenvolvido por Karl Erik Sveiby evidencia a tentativa empreendida para desenvolver critérios que auxiliem a gestão, mensuração, registro e evidenciação do capital intelectual. É utilizado desde 1993 pela empresa dinamarquesa de consultoria PLS-Consult; pela sueca Celemi, uma empresa que desenvolve e vende ferramentas de treinamento; e pela WM-data, a maior empresa da Suécia especializada em softwares e consultoria.

\subsubsection{Metodologia de Annie Brooking}

BROOKING (1999, p.4), fundadora e diretora executiva do The Technology Broker (Reino Unido), desenvolveu uma fórmula para mensuração do capital intelectual, que pode ser representada da seguinte forma:

Valor da empresa = Ativos tangíveis + capital intelectual

Onde:

Ativos tangíveis $=$ capital financeiro, $\mathrm{e}$

Capital intelectual $=$ ativos de mercado + ativos humanos + ativos de infra-estrutura + ativos de propriedade intelectual.

Na Figura 3 apresenta-se o modelo para mensuração do capital intelectual desenvolvido por Annie Brooking.

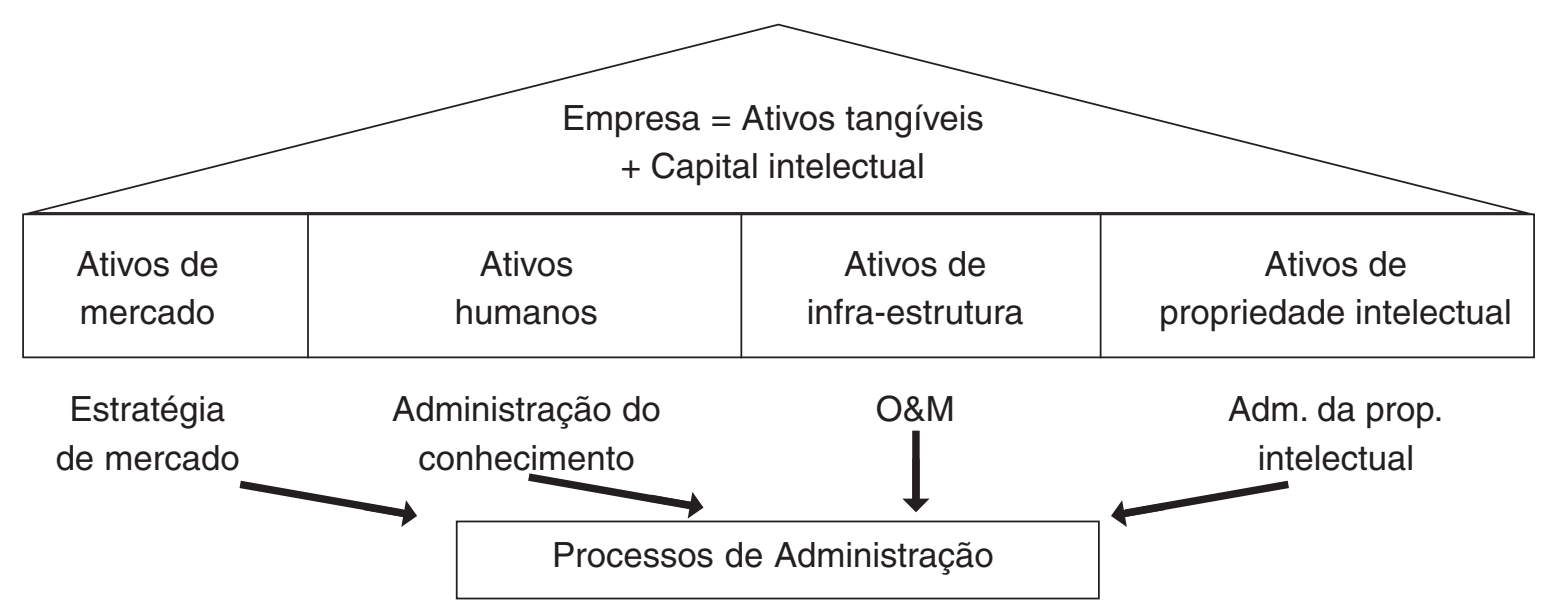

FONTE: BROOKING (1999, p.4)

\section{Figura 3 - Mensuração do capital intelectual segundo Brooking}

Segundo essa concepção, o capital intelectual pode ser dividido em quatro categorias: ativos de mercado, ativos humanos, ativos de infra-estrutura, e ativos de propriedade intelectual.

a) Ativos de mercado

Representam o potencial que a empresa possui em decorrência dos intangíveis que estão relacionados ao mercado, tais como marcas, clientes, lealdade dos clientes, negócios em andamento, canais de distribuição e franquias, que podem estabelecer alguma estratégia de mercado diferenciada.

b) Ativos humanos

Consistem na administração do conhecimento, representada pelos benefícios que o indivíduo pode proporcionar para as organizações por meio de sua expertise, criatividade, conhecimento, habilidade para resolver problemas, visto de forma criativa e dinâmica.

c) Ativos de infra-estrutura

São representados pelas tecnologias, metodologias e processos empregados como cultura, sistema de informação, métodos gerenciais, aceitação de riscos e banco de dados de clientes.

d) Ativos de propriedade intelectual

Consistem na administração da propriedade intelectual, representada pelos ativos que necessitam de proteção legal para proporcionarem às organizações benefícios como know-how, segredos industriais, copyright, patentes e designs.

O modelo de Brooking não inclui nenhum relatório específico sobre a mensuração do capital 
intelectual. Entretanto, a avaliação ocorre dentro da empresa por meio da escolha de um foco que permita alguma medição, para que os gerentes tenham sua própria compreensão a respeito do valor do capital intelectual de suas empresas.

\subsection{Contabilização do capital intelectual}

O debate sobre como efetuar o registro contábil de ativos intangíveis vem ganhando impulso em todo o mundo nos últimos anos, concentrando-se na questão de como gerar um relatório sobre os intangíveis. Segundo SVEIBY (1998, p.221), esse debate veio à tona em conseqüência da ampla divulgação da aquisição, no final da década de 1980, de grupos de empresas com produtos ricos em marcas registradas. Na década de 1990, o foco do debate passou a ser sobre os ativos que os presidentes das empresas rotineiramente chamam de "nossa maior riqueza", isto é, os funcionários.

SVEIBY (1998, p.221-222) relata que a Suécia lançou a prática dos demonstrativos de pessoal. Os relatórios anuais, hoje, sobretudo os das empresas públicas, normalmente contêm uma ou duas páginas com números e gráficos-chave sobre o assunto.

Duas empresas suecas, a WM-data e a Skandia AFS, são líderes internacionais nesse setor e abordaram o assunto de duas formas diferentes. A WMdata avaliou os ativos intangíveis durante mais de uma década. Desde 1989 a empresa inclui em seus relatórios anuais uma seção sobre o assunto e, com seis anos de experiência utilizando esses indicadores, é a pioneira no campo. Os indicadores são utilizados para fins de acompanhamento da estratégia da WM-data, mas mantêm uma postura discreta em seus relatórios públicos.

A Skandia - Assurance \& Financial Services (AFS), atuando na área de seguros de vida e de serviços financeiros, foi a escolhida para implementar os trabalhos de pesquisa e desenvolvimento do modelo de mensuração, posteriormente estendido às demais empresas do grupo.

Leif Edvinsson foi escolhido para ser o diretor de capital intelectual, logo considerado o primeiro no mundo a ter este cargo, tendo sido também a pioneira na contratação de um Controller para capital intelectual, quando, em 1993, Elizabeth Gemzell-Mikkelsen assumiu a função, tendo como meta principal, dentre outras, identificar a mensurabilidade dos ativos intangíveis, desenvolver tecnologias para compartilhar o conhecimento, aperfeiçoar, cultivar e capitalizar o capital intelectual, o que efetuou-se através do levantamento dos valores ocultos da Skandia AFS.

EDVINSSON e MALONE (1998, p.39) relatam que, em 1992, puderam divulgar internamente as três primeiras conclusões de sua equipe de trabalho:

a) o capital intelectual constitui informação suplementar e não subordinada às informações financeiras;

b) o capital intelectual é um capital não-financeiro, e representa a lacuna oculta entre o valor de mercado e o valor contábil; e

c) o capital intelectual é um passivo e não um ativo. ANTUNES (2000, p.96) ressalta que a relação de suplementariedade se deve ao fato de que, em algum tempo no futuro, o capital intelectual será convertido em um valor monetário. Assumir tal posição contribui para reforçar a impossibilidade desses elementos serem, no momento, incorporados às demonstrações financeiras ou, especificamente, ao Balanço Patrimonial.

A segunda conclusão é a percepção da existência de determinados números de pilares que se acrescentam aos valores não-financeiros de uma corporação, criando a notória coluna entre valor contábil e valor de mercado. Tais pilares - tecnologia, valores, e capital intelectual - incorporados à estratégia empresarial - alteram sobremaneira a forma de avaliar uma empresa.

O entendimento do capital intelectual como um passivo a ser tratado de maneira idêntica ao Patrimônio Líquido pode, num primeiro momento, causar certo espanto. Entretanto, conforme afirma ANTUNES (2000, p.97):

Numa análise um pouco mais atenta à filosofia do capital intelectual, verifica-se ser este o procedimento mais coerente, pois, em vez de o capital intelectual ser tratado como um item a ser amortizado e reduzindo o Balanço Patrimonial, retrata a idéia de valor corporativo, ao considerá-lo como um empréstimo feito pelos clientes, empregados, etc., vistos como fonte de capital (recursos).

Nesse contexto, explica-se que esses recursos, no sentido de origem, serão aplicados no 
ativo intangível, representado pelas propriedades intelectuais, tecnologias, competências, relacionamentos com clientes e a comunidade, que podem gerar benefícios futuros para a entidade, valorizando, assim, sua marca e, conseqüentemente, atribuindo-Ihe valor corporativo.

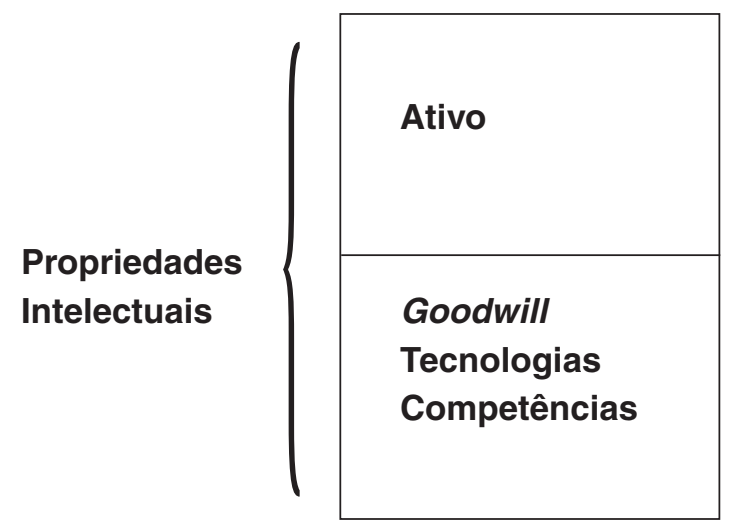

FONTE: EDVINSSON e MALONE (1998, p.39)
A Figura 4 retrata os resultados obtidos na Skandia, durante o ano de 1992, quando a equipe dirigida por Leif Edvinsson tinha por objetivo principal incentivar o crescimento e desenvolver o capital intelectual da empresa como um valor visível e permanente, que complementasse o balanço patrimonial.

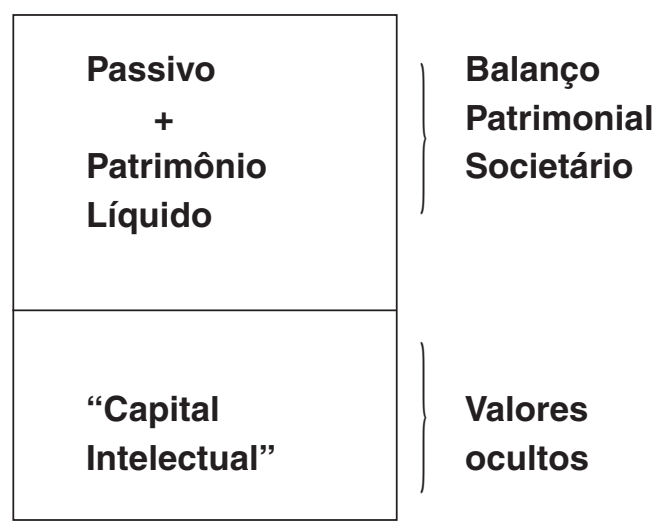

Figura 4 - representação gráfica do capital intelectual no balanço patrimonial

Percebe-se que o capital intelectual, representado pelas origens de recursos, através dos valores ocultos que são aplicados no goodwill, nas tecnologias e competências representadas pelas propriedades intelectuais, não são visíveis no sistema contábil tradicional.

Ainda, na Suécia, a Celemi, uma empresa que desenvolve e vende ferramentas de treinamento, utilizou uma "auditoria de conhecimento" para apresentar seus ativos intangíveis. $O$ balanço patrimonial invisível da Celemi contém ativos intangíveis que podem ser classificados em três categorias principais: estrutura externa, estrutura interna e competência do pessoal, conforme relata SVEIBY (1998, p.229-231):

a) Estrutura externa

Os nossos clientes são uma estrutura externa de relações com clientes e fornecedores, assim como as marcas, os contratos e a reputação ou imagem.

b) Estrutura interna

A organização é uma estrutura corporativa interna, que consiste em patentes, conceitos, contratos com fornecedores, modelos e sistemas de computação e suporte, inclusive para fins de gerenciamento em geral.

c) Competência individual

O quadro de pessoal representa a competência combinada dos funcionários da Celemi, incluindo sua capacidade para agir em diversas situações. $O$ valor das pessoas é que elas são os únicos verdadeiros agentes dentro da empresa. Todos os ativos e estrutura, visíveis ou invisíveis, são resultado da ação humana e dependem de competência e energia para continuarem existindo.

Percebe-se, diante do exposto, que a evidenciação do capital intelectual, assim como sua contabilização, embora informal, já é algo factível nas empresas suecas e que, portanto, em algum momento, outras organizações tenderão a perceber a necessidade de se evidenciar seu capital intelectual.

Quanto a isso, considerando-se que o capital intelectual é um fator resultante da revolução tecnológica, o FASB $(1999$, p.2) propõe um padrão para a mensuração, registro e evidenciação do capital intelectual, mencionando o propósito principal:

O objetivo de se informar a mensuração do capital financeiro quantitativo e intelectual é fornecer medidas comparáveis dos valores intangíveis globais dentro das empresas e fornecer medidas de desempenho baseadas no capital intelectual das companhias. Esta informação será utilizada para comparações dos valores do capital intelectual entre empresas analisadas. Também irá permitir 
comparações de contribuições feitas por certos componentes significativos de capital intelectual aos potenciais de ganhos excedentes da empresa.

Ativo tangível

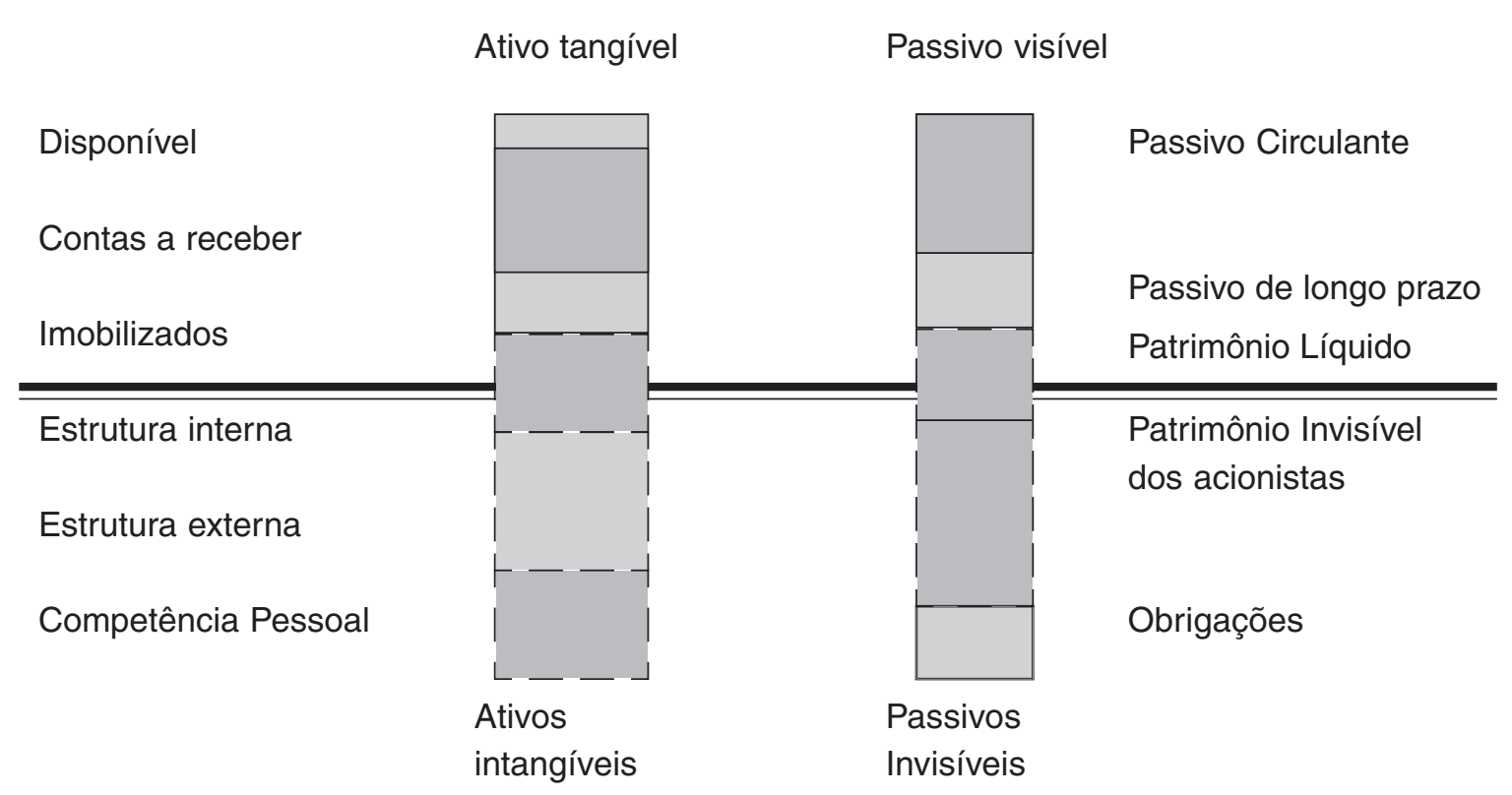

FONTE: SVEIBY (1998, p.13)
SVEIBY (1998, p.13) propõe um modelo de Balanço Patrimonial para registrar o capital intelectual, conforme evidenciado na Figura 5.

Figura 5 - demonstração do capital intelectual no balanço patrimonial

Este modelo, que é utilizado pela empresa sueca Celemi, demonstra, na parte superior, os componentes visíveis do balanço patrimonial tradicional. Especifica, no lado direito, o passivo visível, ou seja, as origens de recursos por meio de capital próprio (patrimônio líquido) e pelo capital de terceiros (passivo circulante e passivo de longo prazo). No lado esquerdo é demonstrado o ativo tangível, ou seja, as aplicações dos recursos originados pelos passivos, constituídas do disponível, contas a receber e imobilizados.

$\mathrm{Na}$ parte inferior da figura são evidenciadas as origens de recursos, que são obtidos por meio do capital intelectual representado pelos passivos invisíveis, e que são aplicados nos ativos intangíveis das organizações.

Segundo SVEIBY (1998, p.12), a diferença entre o valor dos recursos tangíveis e os recursos invisíveis é o valor de mercado, que pode ser classificado em três grupos, representados: pela estrutura externa, estrutura interna e a competência pessoal.

O valor total dos ativos intangíveis da Celemi, no final de um determinado período, não pode ser mensurado com uma grande dose de certeza. Porém, conforme SVEIBY (1998, p.229), "o balanço patrimonial invisível é muito maior do que seu balanço patrimonial visível, e o que mais interessa para os acionistas da Celemi é se o valor dos ativos intangíveis está aumentando e utilizado de forma eficiente, e isso pode ser afirmado com alguma certeza."

A propósito, SVEIBY (1998, p.230) argumenta que é importante observar que as medidas subjetivas de valores ocultos ou mesmo aparentes, mas de efeitos qualitativos ou implícitos, sempre foram incorporadas a qualquer avaliação, mesmo que estivessem nas notas explicativas ou nos relatórios da administração, isto é, em se tratando de grandes corporações, multinacionais ou não, estivessem em matérias de periódicos especializados em administração e nos jornais ou, ainda, informalmente obtidas. Explica que o que se pretende dizer é que, de alguma forma, essas informações sempre foram buscadas, pode-se dizer até que aleatória ou empiricamente, sem qualquer metodologia sistêmica, 
e que hoje o modelo desenvolvido pela Skandia procura uma padronização para essas informações, que antes eram obtidas informalmente.

\subsection{Influências da mensuração do capital intelectual no processo de gestão}

As informações contidas num relatório de capital intelectual são de interesse tanto dos gestores quanto dos usuários externos, especialmente dos acionistas. Quanto ao aspecto gerencial, julga-se oportuno enfatizar sua utilidade, considerando que as medições de capital intelectual, se bem gerenciadas, contribuem para que a empresa possa buscar seu aprimoramento.

EDVINSSON e MALONE (1998, p.197) afirmam que, "em vez de substituir o sistema atual de medições financeiras, produto de gerações, a mensuração do capital intelectual na realidade o complementa e o amplia."

BROOKING apud ANTUNES (2000, p.122) enfatiza que "o conhecimento do capital intelectual é uma fonte rica de informações sobre a organização em sua totalidade". Também é um instrumento valioso para confirmar a habilidade da organização para atingir seus objetivos, planificar a pesquisa e desenvolvimento, fornecer um foco de informações para programas de educação organizacional e treinamento, analisar o valor da empresa e ampliar a memória organizacional.

De acordo com ANTUNES (2000, p.122), esses aspectos ressaltam as vantagens de se identificar o capital intelectual de uma organização, podendo melhorar as informações contábeis para fins de gestão, conforme os seguintes aspectos:

a) o conhecimento do capital intelectual identifica os recursos necessários em ativos intangíveis, cujo desconhecimento, por vezes, impede a consecução de um planejamento estabelecido; isso significa que o planejamento estratégico pode ser prejudicado por depender de alguns elementos intangíveis e a organização não ter certeza de que dispõe ou não de tais recursos e, em caso positivo, a quantidade e possibilidade de geração futura;

b) por meio do conhecimento do capital estrutural pode-se distinguir as diferenças entre criação de patentes, desenvolvimento de novos designs e de novos produtos, compreendendo as vantagens competitivas que cada um desses elementos possui;

c) no caso da redução do número de funcionários, o conhecimento do capital humano impede que os cortes afetem pessoas com capacidade e know-how valiosos para as organizações;

d) o conhecimento do capital humano também contribui para a decisão de investimentos em treinamentos direcionados às necessidades identificadas em seus ativos humanos, bem como proceder a uma avaliação posterior, a fim de mensurar os benefícios a si trazidos;

e) o conhecimento do capital estrutural (foco no processo) contribui para a decisão de investimento em tecnologia da informação; a propagação e massificação da tecnologia da informação têm levado empresas a investirem grandes quantidades de dinheiro em novos sistemas de informação; uma avaliação da estrutura da tecnologia da informação disponível contribui para identificar as necessidades de novos investimentos, bem como para avaliar a utilização dos sistemas implantados e o retorno que estão dando para a empresa; e

f) o conhecimento detalhado que o modelo de avaliação dispõe sobre os clientes fornece uma visão bem mais abrangente das condições atuais e futuras da empresa relacionadas a esse foco.

Do ponto de vista externo da organização, a mensuração do capital intelectual poderia contemplar os seguintes aspectos:

a) os relatórios divulgando os indicadores do capital intelectual são subsídios valiosos para os analistas e financiadores, pela projeção da futura capacidade da empresa gerar caixa;

b) para os acionistas, esses relatórios são de fundamental e significativa importância, pois, de acordo com EDVINSSON e MALONE (1998, p.9), "as fábricas, equipamentos e terrenos, não oferecem mais muitas indicações sobre a competitividade atual ou o potencial de lucros futuros de uma empresa."

c) sua divulgação pode explicar a diferença entre o valor contábil e o de mercado das organizações, mesmo não sendo de forma objetiva. Entende-se que a contabilidade busca, também, mensurar o real valor da empresa, a fim de 
satisfazer eficazmente a necessidade de informações de seus usuários internos e externos, sejam elas de natureza quantitativa ou qualitativa. A esse respeito, novas questões devem ser levantadas, debatidas e desenvolvidas, especialmente as relacionadas aos itens intangíveis.

\section{A PESQUISA}

O termo "capital intelectual" é encontrado na literatura sob várias outras formas correlatas, tais como patrimônio do conhecimento, gestão do conhecimento, competências e habilidades, ativos intangíveis, capacidade de inovação, inteligência competitiva, gestão de pessoas e processos, entre outras, sendo difícil encontrar um denominador comum. São esses fatores dinâmicos e ocultos que dão sustentação à empresa visível, formada por edifícios, máquinas, pessoas e produtos. E devem, de alguma forma, vir à tona. É preciso encontrar alguma forma de mensurá-los, registrá-los e evidenciá-los para que sejam representados e apresentados, da forma mais adequada, aos usuários das informações.

Alguns organismos internacionais, empresas de consultoria e empresas transformadoras reconheceram essa dificuldade, bem como a necessidade de adaptação das informações contábeis à moderna economia e já realizam estudos a respeito. Entre os organismos internacionais, pode-se citar o Instituto Americano de Contadores Públicos - AICPA, a Comissão de Valores Mobiliários - SEC, o Conselho de Padrões de Contabilidade Financeira - FASB, todos dos Estados Unidos. No que concerne às empresas de consultoria, pode-se mencionar a Ernst \& Young, Saatchi \& Saatchi, McKinsey \& Company, entre outras. No que diz respeito às empresas transformadoras é interessante destacar as suecas WM-data, Skandia e Celemi, que são líderes internacionais neste assunto, bem como a empresa dinamarquesa PLSConsult. Todas elas já elaboram e publicam relatórios anuais complementares às demonstrações contábeis tradicionais sobre seu capital intelectual.

É, pois, nessa perspectiva que se procurou abordar, neste artigo, a questão do tratamento contábil que é aplicado ao capital intelectual, sob a ótica do processo de gestão empresarial. Entende-se, também, que apesar do enorme desafio que a contabilização do capital intelectual representa para os pesquisadores e praticantes da Contabilidade, são relativamente poucos os esforços de pesquisa que têm este tema sob uma perspectiva contábil empírica.

STEWART (1998, p.56) assevera que, "quando uma empresa é comprada por um valor superior ao seu valor contábil, essa diferença normalmente consiste em ativos intelectuais", os quais não aparecem nos balanços contábeis tradicionais. Complementa dizendo que, "os contadores simplesmente subtraem o valor contábil do preço de compra e chamam a diferença de fundo de comércio, um termo que, essencialmente, não significa nada."

Neste sentido, para o estudo foram relacionadas duas empresas de capital aberto de Santa Catarina, que apresentam valor de mercado superior ao valor contábil, conforme verificado em suas respectivas demonstrações contábeis.

A primeira empresa pesquisada é considerada de grande porte, atua no segmento têxtil e apresentou, nos últimos dois anos pesquisados, uma variação positiva entre o valor de mercado e o valor contábil de $24,26 \%$ e $12,19 \%$, respectivamente.

A Segunda empresa pesquisada, também é de grande porte, atua no segmento de informática e telecomunicações e apresentou nos dois últimos anos pesquisados, uma variação positiva entre o valor de mercado e o valor contábil de $72,48 \%$ e $78,70 \%$, respectivamente.

Na escolha das empresas também despertou interesse o seu estilo gerencial, caracterizado pela estratégia de criar valor aos acionistas e a sua expansão gradativa, tanto em termos de mercado quanto de investimentos. Desse modo, a primeira empresa, com vistas à manter o sigilo das suas estratégias, aqui foi denominada de empresa "M". Iniciou suas atividades em 1964 e tem como ramo de atividade preponderante a exploração da indústria e comércio do vestuário, de cama, mesa e banho, de tecidos de fibras e materiais têxteis. A outra empresa, denominada empresa "W" foi fundada em 1961 e tem como ramo de atividade a industrialização, desenvolvimento e comercialização de motores elétricos monofásicos e trifásicos, máquinas elétricas girantes, componentes elétricos industriais; sistemas de processos e automação de manufaturas; sistemas de variação de velocidade, quadros elétricos; transformadores de força e distribuição; tintas, vernizes, diluentes, breu, terebentina, esmaltes e seus derivados; e a exportação de produtos. 
Para verificar o tratamento contábil dispensado ao capital intelectual nas duas empresas, os dados foram coletados nos meses de fevereiro, março e abril de 2001, por meio de um roteiro de entrevista semiestruturado, com questões abertas, aplicados a um total de oito gestores das mesmas.

Assim, sob o ponto de vista teórico, acredita-se que este trabalho possa representar uma contribuição para uma futura proposta de sistematizar a contabilização do capital intelectual, considerandose que a teoria da contabilidade, de certa maneira, na esteira das transformações econômicas e sociais, também tem evoluído, tanto que suas concepções e a compreensão da necessidade de mensuração e contabilização do capital intelectual já é algo factível.

No que diz respeito à contribuição prática, a presente pesquisa também poderá propiciar aos gestores das empresas investigadas um melhor entendimento sobre a sua situação de evidenciação, ao se relacionar as informações do capital intelectual com as demais informações divulgadas pelas demonstrações contábeis tradicionais.

\section{DESCRIÇÃO E ANÁLISE DOS RESULTADOS}

Não se procurou, nesta análise, obter um entendimento conjunto do tratamento contábil do capital intelectual nas duas empresas, mas sim, apontar semelhanças entre os casos, que possibilitem compreender, como esse assunto está sendo entendido, assimilado e praticado nas mesmas.

Percebeu-se que as duas empresas, desde a sua fundação, baseiam sua missão em princípios emanados de seus fundadores. Observou-se também, pelas respostas obtidas na pesquisa, que as duas empresas apresentam semelhanças em seus princípios, os quais denominam de "cultura da empresa".

Identificou-se certa semelhança também nas duas empresas pesquisadas quanto à socialização do conhecimento entre os funcionários e gestores, que se dá por meio da participação periódica nos diversos programas internos que são mantidos e incentivados com esse propósito.

A socialização do conhecimento é o processo pelo qual as experiências são compartilhadas e o conhecimento tácito ou modelos mentais e habilidades técnicas são criados. A respeito, TERRA (2000, p.67) esclarece que a socialização do conhecimento, na prática, ocorre mediante atividades como treinamento no local de trabalho, sessões informais, brainstormings e interações com os clientes, entre outras.

Perguntou-se aos entrevistados se o volume de gastos, no último exercício, foi maior com a aquisição de máquinas e equipamentos do que com as áreas voltadas à pesquisa e desenvolvimento (P\&D) e treinamento dos funcionários. As respostas nas duas empresas foram semelhantes, esclarecendo que já são previamente programados e orçados, através do planejamento estratégico realizado anualmente, os percentuais a serem destinados para investimentos em maquinários, pesquisa, treinamento e desenvolvimento, e que esses guardam uma certa proporcionalidade, dependendo da época e da estratégia a ser adotada pela empresa.

Sobre essa questão, XAVIER (1998, p.119) diz que "só se justificam maiores investimentos em maquinários e equipamentos quando a empresa se encontra em expansão, implantação, fusão ou atualização tecnológica", e que "a continuidade dessa política pode levar a empresa à extinção." Porque a matéria-prima básica do capital intelectual é a informação que as pessoas adquirem e a transformam em conhecimentos, os quais devem ser utilizados pelas organizações como diferencial competitivo.

Quanto ao capital estrutural (capital organizacional, capital de inovação e capital de processos), verificou-se, nas duas empresas pesquisadas, que é chamado de "gestão de processos", onde todos os procedimentos para a geração de projetos, processos de produção, desenvolvimento de novas linhas de produtos e suas respectivas modificações ou melhorias, estão sistematizados e documentados, de acordo com o sistema de qualidade de cada empresa.

A tecnologia, nessas empresas, está baseada num conjunto de conhecimentos, informações e experiências acumuladas, que estão documentadas e, periodicamente, são aplicadas e difundidas para consolidação e perenidade do conhecimento.

Nas empresas pesquisadas, os grupos de trabaIho responsáveis pela execução de cada projeto de pesquisa são multifuncionais e multidepartamentais. 
Desde a definição dos objetivos do projeto até a aprovação do lote-piloto, todos os participantes dos diversos departamentos, nas duas empresas, são envolvidos. O mesmo ocorre na execução do projeto. Verificou-se, também, que é a maneira utilizada para praticar a engenharia simultânea, em que todos são co-responsáveis pelo cumprimento dos prazos e objetivos. Nesse aspecto, cabe ao coordenador do projeto a responsabilidade de envolver as diversas áreas afins ao projeto e conduzi-lo dentro do cronograma, dividindo as tarefas de acordo com a área de atuação de cada participante.

Existe um instrumento formal, adotado nessas empresas, que reúne todos os projetos de pesquisa e desenvolvimento, que é chamado de Programa de Pesquisa e Desenvolvimento. Este programa é elaborado, anualmente, por todas as áreas técnicooperacionais, em ambas as empresas. O acompanhamento é feito trimestralmente, sendo que a participação dos funcionários na distribuição dos lucros está condicionada, além de outros fatores, ao desempenho do programa de desenvolvimento tecnológico.

No que se refere ao capital de clientes, ficou caracterizado que é o valor dos relacionamentos que os colaboradores da empresa mantêm com os clientes que transforma o capital intelectual em dinheiro. Vale ressaltar que, muitas vezes, as empresas apresentam melhorias óbvias na qualidade de seus produtos e serviços; entretanto, nem só por isso conseguem a satisfação de seus clientes. As conexões mais valiosas pertencem às pessoas, que verificam o que acontece com os clientes. Organizações inteligentes investem e gastam o menor tempo possível em trabalhos que os clientes não valorizam. Atualmente, tanto clientes, quanto fornecedores, possuem e têm acesso a muito mais informações do que tinham antes. Ter acesso a essas fontes representa ameaças e oportunidades às empresas.

Outra questão que diz respeito ao capital de clientes é que a parceria entre uma empresa e seu cliente pode ser bastante beneficiada quando existe a divisão de ganhos, contribuindo para a fidelização do cliente e um diferencial competitivo. Na empresa "W", a satisfação do cliente é uma das principais metas perseguidas. Os requisitos, anseios e expectativas dos clientes são constantemente observados e a atuação da empresa é continuamente reavaliada num processo recíproco e dinâmico.
Na empresa "W", uma outra questão interessante foi apontada, quanto ao relacionamento com clientes. Nessa empresa existe uma pesquisa formal de satisfação, realizada trimestralmente, pela qual são encaminhados formulários a um número preestabelecido de clientes. Todos os formulários, com respostas de "insatisfeito" ou "muito insatisfeito", são tratados individualmente, por meio de contato com os clientes, buscando conhecer a causa da insatisfação e com proposta de ações corretivas e preventivas. Assim, existe mais um canal de comunicação com os clientes, que desse modo podem externar todos os problemas que levam às suas insatisfações e garantir que essas informações sejam acompanhadas diretamente pela fábrica.

No que se refere às perspectivas estratégicas, verificou-se que as duas empresas utilizam-se de um planejamento estratégico, o que, de modo geral, objetiva, entre outros, assegurar o crescimento contínuo da empresa e a capacitação necessária para atuar no mercado nacional e internacional.

O planejamento estratégico contempla, também, o desenvolvimento de pessoal; o domínio de tecnologias com investimentos em pesquisa e desenvolvimento; melhorias das condições de trabaIho, focalizando, principalmente, a segurança e a saúde; melhorias na rede de assistência técnica, objetivando assegurar o pronto atendimento dos clientes nos serviços pós-venda; a reestruturação do modelo de vendas para acompanhar a evolução tecnológica e do mercado e, também, identificar as necessidades dos clientes.

No que se refere à perspectiva financeira, percebeu-se que as empresas pesquisadas não dispõem de instrumentos sistematizados para mensurar, registrar e comunicar suas informações, que guardem alguma semelhança com as metodologias mencionadas nos pressupostos teóricos do capital intelectual. Essas empresas dispõem de um sistema de informações integrado com o próprio planejamento estratégico. Nele estão definidas as diretrizes e estabelecidas as principais metas.

Com base nas metas principais, são desencadeadas as metas por departamento, que dão suporte aos programas de qualidade e produtividade e ao sistema de avaliação de plano de atividades. Tal ocorre por meio do Sistema de Informações Gerenciais (SIG). Este sistema está estruturado para 
prover os departamentos das empresas com informações passadas, presentes e compará-las com os objetivos a serem alcançados em relação à operação interna e ao ambiente externo das empresas. Ele dá suporte às funções de planejamento, execução e controle das empresas, fornecendo informações uniformes, medindo o desempenho e assistindo na tomada de decisão.

Em relação à questão da aquisição do conhecimento, percebeu-se que essa perspectiva emerge num processo de criação de valor baseado na interação entre as perspectivas estratégica, operacional e financeira, que convergem o conhecimento individual das pessoas em conhecimento organizacional, de modo a possibilitar respostas através dos indicadores específicos, que são gerados por um sistema de medição de desempenho.

A partir dessa associação, são elaborados os planos de ação para melhorar o desempenho desses indicadores que, por sua vez, influenciam as metas a serem atingidas pelos departamentos. Como as metas dos departamentos são desdobradas a partir das metas organizacionais, quando estas são atingidas em nível departamental, também as metas organizacionais são atingidas.

Os indicadores de desempenho definidos para esta finalidade, que, por motivos estratégicos das empresas pesquisadas não foram divulgados, abrangem cinco dimensões da qualidade: tempo, custo, qualidade, moral e segurança. Esses indicadores, que estão completamente harmonizados e claramente definidos, medem o lead-time, a eficiência, a eficácia, o custo do departamento, a variação entre o custo realizado e o custo orçado para o ano, os custos da qualidade, o refugo, o retrabalho, o nível das não-conformidades, o absenteísmo, a satisfação do clima organizacional, o número de acidentes, a taxa de gravidade e a freqüência dos acidentes de trabalho.

Como faz parte dos princípios das empresas pesquisadas o investimento contínuo em treinamento, educação e desenvolvimento de seus colaboradores, o planejamento estratégico leva em conta esses aspectos, considerando os principais planos de gestão de pessoas, que são estabelecidos pela direção da empresa, tanto a curto quanto a longo prazo.

Constatou-se que as duas empresas investigadas não possuem, sistematizada, alguma forma de evidenciar os recursos investidos e o potencial de geração de resultados do capital intelectual, com vistas ao processo de gestão. Entretanto, utilizam-se de um sistema de informações gerenciais, estruturado, sistematizado e formalizado conforme suas necessidades.

Perguntou-se, também, aos entrevistados, como os demonstrativos financeiros tradicionais se relacionam com a avaliação representada pelo capital intelectual. As respostas foram semelhantes nas duas empresas pesquisadas.

"Os demonstrativos financeiros tradicionais em nada se relacionam com a avaliação proposta para o capital intelectual. Para o capital humano, temos algo semelhante denominado balanço social; entretanto, para o capital estrutural, ainda não temos nada parecido." (Gerente de Controladoria da empresa "M")

"Não se relacionam em nada, os indicadores; quando positivos no balanço tradicional, significam uma boa gestão." (Gerente de Controladoria da empresa "W")

Entende-se que essas afirmativas vêm, de alguma forma, confirmar a percepção inicial de que a representação contábil do capital intelectual ainda se encontra muito longe de ser algo factível nas empresas, de um modo geral. Acredita-se que o maior desafio, no momento, consiste em entender e sistematizar sua medição e apresentação.

Uma outra questão que foi perguntada relacionase com a identificação da forma como as informações dos demonstrativos financeiros tradicionais deveriam ser modificadas para incorporar a avaliação do capital intelectual. Esta questão foi elaborada visto que o debate sobre como efetuar o registro contábil de ativos intangíveis vem ganhando impulso em todo o mundo nos últimos anos, concentrando-se, fundamentalmente, na forma de criar um relatório dos bens intangíveis.

"Sabemos que as demonstrações contábeis publicadas são fechadas e de pouca utilidade, e não atendem quase a ninguém; mas é o que se tem, e isso só será mudado quando todos forem obrigados, de alguma forma, a publicar algo novo para prestarem contas à sociedade." (Gerente de Controladoria da empresa "M") 
Considerando-se as respostas às questões e as observações durante a pesquisa, torna-se relevante dizer que o formato contábil existente possibilita que a alta gerência e a diretoria das empresas analise e aprove planos estratégicos internamente. Entretanto, não permite que as empresas reportem, nos mesmos termos, seu desempenho à comunidade e a seus acionistas.

Quanto a isso, SVEIBY (1998, p.186) esclarece que é tentadora a intenção de criar um sistema de avaliação equivalente à contabilidade da partida dobrada, tendo o dinheiro como denominador comum. Justifica que esta "é uma estrutura consagrada com definições e padrões e, por isso, representativa do consenso geral." Entretanto, menciona que se continuarmos avaliando o novo com as ferramentas do antigo, não teremos como perceber o novo. Explica que, não existe diferença entre as medidas financeiras e as demais, ambas são incertas; todas dependem do observador. As principais razões pelas quais as medidas financeiras parecem mais objetivas ou reais é que elas são encontradas em conceitos implícitos do que é uma empresa e existem há tanto tempo que são regidas por definições e padrões. As medidas financeiras influenciam o que vemos e a maneira como agimos. O problema com a tradução de ações em dinheiro é que poucas pessoas em uma organização lidam diretamente com dinheiro. A maioria trabalha utilizando suas competências no serviço aos clientes. O dinheiro é apenas uma procuração para o esforço humano, e que "um sistema contábil de quinhentos anos oferece poucas contribuições para os processos vitais de organizações cujos ativos são, em grande parte, não-financeiros e intangíveis."

Diante disso, identificou-se que as empresas pesquisadas ainda não possuem nenhum critério sistematizado para mensurar, registrar e evidenciar seu capital intelectual, conforme as metodologias e modelos já desenvolvidos para essa finalidade. Constatou-se também, nas duas empresas pesquisadas, que não existe um tratamento contábil sistematizado para o capital intelectual. O que existe em ambas é um conjunto de tecnologias que coloca à disposição os meios necessários à operacionalização do processo decisório, denominado Sistema de Informações Gerenciais - SIG.
"Essa é uma questão a ser estudada no futuro, não temos nada formalizado e, pelo menos por enquanto, não se pensa em desenvolver nada sobre isso. Qual é o custo benefício? É um processo viável?" (Gerente de Controladoria da empresa "W")

Verificou-se que, anualmente, quando da elaboração dos programas de qualidade e produtividade, os dados obtidos pelas diversas fontes são utilizados para o estabelecimento das metas a serem perseguidas por todas as áreas das empresas e os novos desenvolvimentos a serem efetuados no período.

Os indicadores-chave, acompanhados mensalmente pelo sistema de informações gerenciais, são revistos anualmente pelas comissões, quando são estabelecidos novos objetivos. A sua elaboração tem como base informações da concorrência e referências próprias, obtidas em fontes técnicas e administrativas e, mês a mês, os resultados são avaliados pelas gerências de cada área, quando são tomadas ações para corrigir desvios detectados.

Verificou-se que em nível global, nas duas empresas, o SIG reúne em um único documento diversos índices financeiros, econômicos e de mercado, tais como: mercado acionário, evolução de preços e custos, estatísticas de importações, estatísticas de exportações, gráficos e quadros de faturamento, programas de qualidade e produtividade e comparativos de desempenho, que são coletados em diversos bancos de dados.

Percebeu-se que na empresa "W", o acesso às bases de dados centrais, via on-line, através de terminais e redes de microcomputadores distribuídos por todos os setores da empresa, permite o uso permanente do sistema de informações pelos colaboradores, facilitando e agilizando a coleta e análise de dados. Esse processo também é disponibilizado na empresa "M", através da intranet.

Entretanto, apesar dos indicadores consubstanciados SAPA - Sistema de Avaliação do Plano de Atividades, no SIG-Sistemas de Informações Gerenciais e no EVA - Economic Value Added serem acompanhados mensalmente pelas gerências e diretoria e comparados com as metas previstas, contribuindo para o processo de 
gestão das empresas, a contribuição para a contabilização do capital intelectual é praticamente nula, pois esses dados não aparecem nos demonstrativos contábeis tradicionais, e o capital intelectual fica, portanto, sem receber nenhum tratamento contábil específico e sistematizado.

\section{CONCLUSÃO}

O objetivo geral da pesquisa consistiu em verificar o tratamento contábil que é aplicado ao capital intelectual, sob a ótica do processo de gestão, representado pelos conceitos e técnicas que são utilizados e que dão suporte à ação da administração, em empresas com valor de mercado superior ao seu valor contábil.

Assim, observou-se que as empresas pesquisadas não possuem uma forma sistematiza- da e específica para fazê-lo. Entretanto, possuem outras formas, devidamente formalizadas e estruturadas, que atendem às suas necessidades internas de informação para dar suporte ao processo de gestão, tais como o SAPA - Sistema de Avaliação do Plano de Atividades, o SIG - Sistema de Informações Gerenciais e o EVA - Economic Value Added.

Portanto, a partir da análise das respostas dos entrevistados em relação às perguntas elaboradas no roteiro de entrevistas, concluiu-se que as empresas pesquisadas não se utilizam de nenhum tratamento contábil sistematizado e estruturado para mensurar, registrar e evidenciar o capital intelectual, tal como foi abordado no referencial teórico, apesar de possuírem todas as características de gestão voltadas ao conhecimento e serem detentoras de tecnologias de produção e capacidade gerencial. 


\section{REFERÊNCIAS BIBLIOGRÁFICAS}

ANTUNES, Maria Thereza Pompa. Contribuição ao entendimento e mensuração do capital intelectual. 1999. Dissertação (Mestrado em Controladoria e Contabilidade) - Faculdade de Economia, Administração e Contabilidade, Universidade de São Paulo, São Paulo.

\section{Capital intelectual. São Paulo: Atlas, 2000.}

BROOKING, Annie. Intelectual Capital. Core asset for the third millenium enterprise, International Thomson Business Press: Londres, 1996.

BEUREN, Ilse Maria. Modelo de mensuração do resultado de eventos econômicos empresarias: um enfoque de sistema de informação de gestão econômica. 1994. Tese (Doutorado em Controladoria e Contabilidade) Faculdade de Economia, Administração e Contabilidade, Universidade de São Paulo, São Paulo.

Celemi's Intangible Assets Monitor. Disponível em: <http://www.celemi.com/ company/mo- nitor99.asp>. Acesso em: 16 set.2001.

EDVINSSON, L.; MALONE, M. S. Capital intelectual: descobrindo o valor real de sua empresa pela identificação de seus valores internos. São Paulo: Makron Books, 1998.

FASB, Financial Accounting Standards Board. Exposure draft. Proposed statement of financial accounting standards: Disclosure of intellectual capital measurements. Financial accounting series, nr. 333-A., 25 de fevereiro de 1999.

GUERREIRO, Reinaldo. Modelo conceitual de informação de gestão econômica: uma contribuição à teoria da comunicação da contabilidade. 1989. Tese (Doutorado em Controladoria e Contabilidade) - Faculdade de Economia, Administração e Contabilidade, Universidade de São Paulo, São Paulo.
KLEIN, David A. A gestão estratégica do capital intelectual: recursos para a economia baseada em conhecimento. Rio de Janeiro: Qualitymark, 1998.

OLIVER, Richard W. Como serão as coisas no futuro. São Paulo: Negócio, 1999.

OLIVEIRA, Josué Viana de. O Capital intelectual: um paradigma contábil. In: XVI Congresso Brasileiro de Contabilidade, 2000, Goiânia/GO. Disponível em: <http://www.cfc.org.br/congresso/trabalhos/htm>. Acesso em: 28 abr. 2001.

PACHECO, Vicente. Uma contribuição ao estudo da contabilidade de recursos humanos e seu poder de informação. 1996. Dissertação (Mestrado em Controladoria e Contabilidade) - Faculdade de Economia, Administração e Contabilidade, Universidade de São Paulo, São Paulo.

STEWART, Thomas A. Capital intelectual: a nova vantagem competitiva das empresas. Rio de Janeiro: Campus, 1998.

SVEIBY, Karl Erik. A nova riqueza das organizações: gerenciando e avaliando patrimônios do conhecimento. Rio de Janeiro: Campus, 1998.

WIIG, Karl M. Gestão do conhecimento: de onde veio e para onde vai. Revista Empresas \& Tendências. Brasília, n. 48, p. 10-11, maio 1998.

TERRA, José Cláudio C. Gestão do conhecimento: o grande desafio empresarial - uma abordagem baseada no aprendizado e na criatividade. São Paulo: Negócio, 2000.

XAVIER, Ricardo de Almeida Prado: Capital Intelectual: administração do conhecimento como recurso estratégico para profissionais e empresas. São Paulo: STS, 1998. 